\title{
OPEN More frequent and widespread persistent compound drought and heat event observed in China
}

\begin{abstract}
Rong Yu \& Panmao Zhai ${ }^{\bowtie}$
Compound drought and heat event (CDHE) causes severe impacts on agriculture, ecosystem, and human health. Based on daily maximum surface air temperature and meteorological drought composite index data in China, changing features of CDHEs in warm season from 1961 to 2018 is explored at a daily time scale based on a strict and objective definition in this study. Results reveal that CDHEs have occurred more frequently and widely in China, especially since the late 1990s. Notably, such changes are more obvious in Southwest China, eastern Northwest China, northern North China, and the coastal area of southeastern China. A prominent feature is that persistent CDHEs on a daily scale have increased significantly. To better understand climate change of compound extreme events, further studies on the physical mechanism, especially attribution analyses at a regional scale, are urgently needed.
\end{abstract}

Extreme weather and climate events have been widely studied over the past decades ${ }^{1-3}$. Research on changes in extreme heat events and drought events has been conducted in different regions of the world ${ }^{4,5}$. In China, frequency, intensity, and affected areas of extreme heat events show increase trends in most areas ${ }^{6,7}$. Drought has enhanced in North China and Southwest China during the past decades ${ }^{8,9}$. Further studies shown that extreme temperature and drought events have happened more frequently and widely under global warming, and they are projected to further enhance with temperature rising ${ }^{10,11}$. Recently, concurrent drought and heat events seen in 2018 Europe and 2019 Australia have attracted the attention of science community ${ }^{12}$. Such types of compound extreme events induce aggravated impacts on agriculture, ecosystem, water security, and human health ${ }^{13-16}$.

Studies are emerging in compound drought and heat events (CDHEs). As documented, Europe has been widely and frequently threatened by CDHEs in recent years ${ }^{13,17,18}$. In Africa, the increasing trend has been observed and projected for summer drought and heat waves ${ }^{15,19}$. In the United States, a substantial increase in CDHEs has been highlighted ${ }^{20,21}$. Meanwhile, exacerbated CDHEs have been investigated in some regions from different perspectives in China ${ }^{22-24}$.

However, in most previous studies, monthly drought indices were used as a background to explore the changes in CDHEs ${ }^{13,22,25,26}$. Following such approaches, the duration of CDHEs could not be accurately provided to some extent, since daily features based on most previous studies have been obscured. For some other studies ${ }^{23,27}$, dry conditions were used to analyze changes in CDHEs. In that case, those detected and attributed changes are not related to drought directly. As a matter of fact, a CDHE which has mixed impacts of heat weather and drought conditions persisting for several days or weeks can induce serious impacts. Also, the detection and attribution of CDHEs, and feedback between extreme drought and heat events, are very important topics, which require a better index to understand the changing features ${ }^{17,28,29}$.

In this study, meteorological drought composite index (MCI), a daily drought index used in China's drought monitoring ${ }^{30,31}$, is applied to derive CDHEs in this study. Considering that changes in drought and heat events bring about a disastrous impacts on agriculture, ecosystem, and human health, spatial-temporal changes in daily CDHEs during warm season (from May to October) of 1961-2018 in China are investigated. Besides, intensity, frequency, persistence, and spatial distribution are important properties for understanding extreme event changes ${ }^{32,33}$. Based on the most updated datasets and the newly defined CDHE index, these changes in the above mentioned properties of CDHEs in China are also studied and reflected in this investigation. 

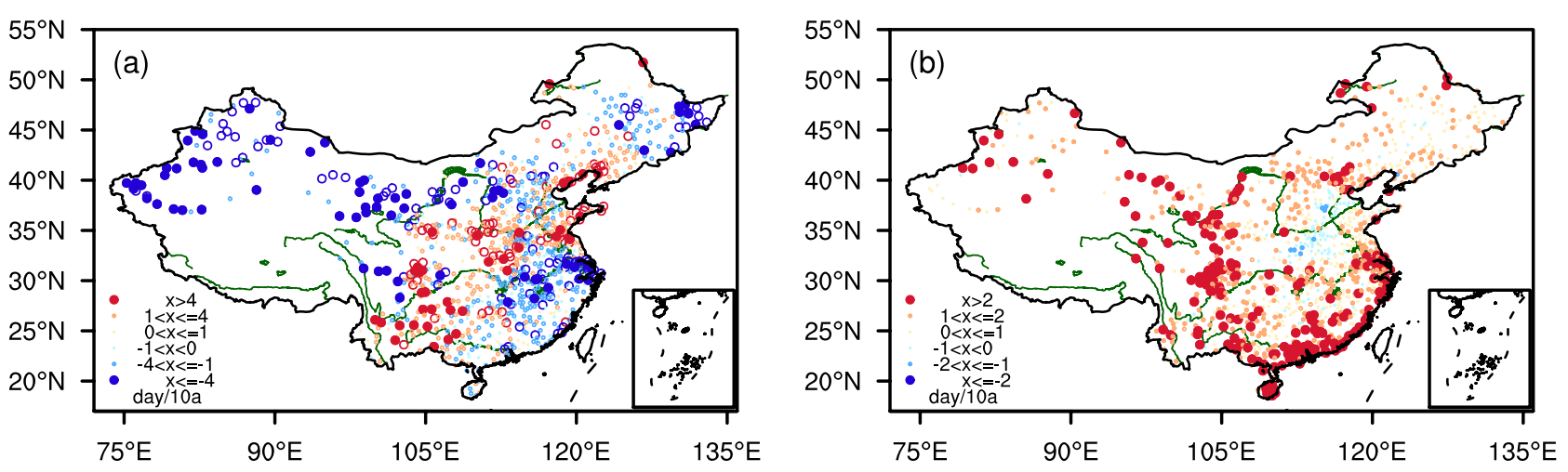

Figure 1. Spatial distribution of trends in the number of drought days (a) and trends of heat days (b) in the warm season of 1961-2018 in China. Statistical significance is detected using Mann-Kendall non-parametric test and the linear trend is quantified using Theil-Sen trend estimation (filled dots refer to stations with statistical significance at $90 \%$ confidence level). Maps are generated using NCAR Command Language (The NCAR Command Language (Version 6.6.2) [Software]. (2019). Boulder, Colorado: UCAR/NCAR/CISL/TDD. https://www.ncl.ucar.edu/).
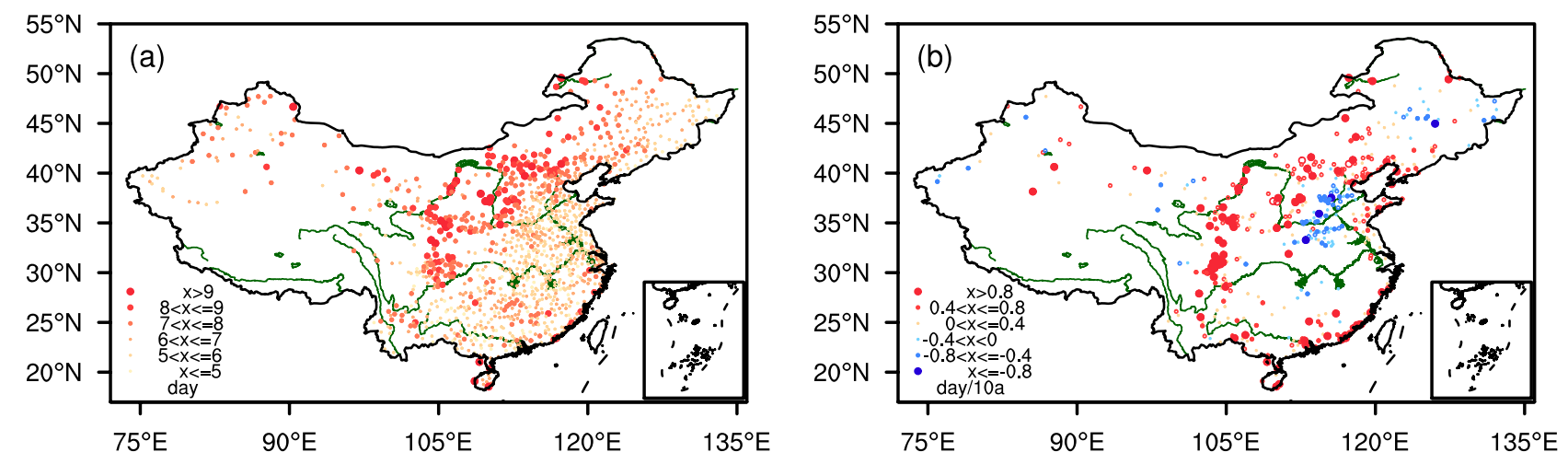

Figure 2. Distribution of the climate average and trend of CDHE days in the warm season during 1961-2018 ((a) average of all compound days for the period of 1961-2018; (b) trend of all CDHE days. Statistic significance is detected using Mann-Kendall non-parametric test and the linear trend is quantified using Theil-Sen trend estimation(Filled dots stand for the station with statistical significance at 90\% confidence level)). Maps are generated using NCAR Command Language (The NCAR Command Language (Version 6.6.2) [Software]. (2019). Boulder, Colorado: UCAR/NCAR/CISL/TDD. https://www.ncl.ucar.edu/).

\section{Changes in compound drought and heat events}

Based on the long-term time series of daily MCI and daily maximum surface air temperature, the trends in drought (Fig. 1a) and heat events days (Fig. 1b) are separately analyzed firstly. Results indicate that number of drought days illustrates a decreasing trend in southeastern China and Northwest China from 1961 to 2018, while it shows an increasing trend in Southwest China and North China (Fig. 1a). Such a changing pattern is generally consistent with that the conclusion on changes in precipitation by Zhai et al. ${ }^{34}$. As for Southwest China and North China, dry-spell has prevailed in recent years, thus triggered drought events frequently happened ${ }^{33}$.

For the heat events, Fig. $1 \mathrm{~b}$ reveals that the number of heat events days shows a widespread increasing trend in China. Different from drought, it has increased significantly in Northwest China, southeastern China, South China, and the Yangtze River Valley. However, there exists a negative trend in the number of heat event days in southern North China, where the downtrend is possibly reflected as a regional response to inter-decadal and inter-annual variability ${ }^{35,36}$. Also, some other studies suggested that such a unique regional changing feature under global warming is possibly attributed to changes in aerosol, and regional land use and management ${ }^{1}$.

As for drought and heat events, Fig. 2a displays the spatial distribution of the average number of CDHE days in the warm season. As illustrated, CDHEs increase in frequency from south to north in China. Notably, the average increase is more than 10 days in northern North China, Northwest China, and Southwest China. It is more frequent in the arid or semi-arid climate zones. Figure $2 \mathrm{~b}$ provides the trend distribution for the number of CDHE days. The results indicate that the number of CDHE days has increased in most parts of China with a trend of more than 0.8 day/10a. However, it has decreased in southern North China and some eastern parts of Northeast China. Similar evidence is also identified by some regional research studies in China ${ }^{37-39}$.

To further understand why some regions in China show decrease trends in CDHEs, we have compared with evidence shown in Fig. 1a,b. Obviously, the decreasing trend in the number of CDHE days in southern North China is mainly because of decrease in the number of heat event days, that in the eastern part of Northeast China 


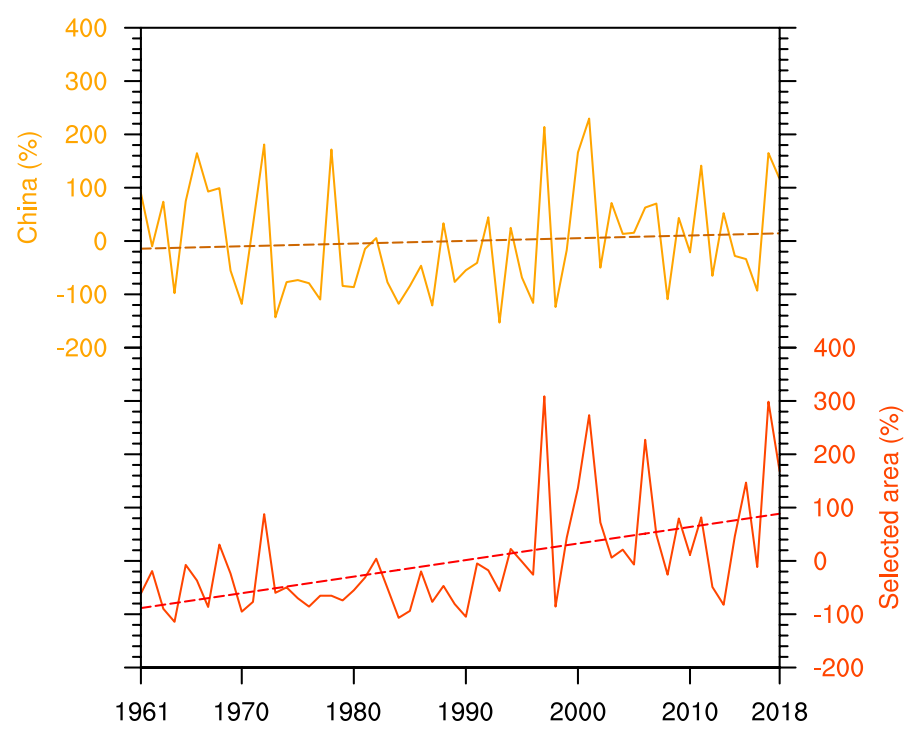

Figure 3. Normalized time series of the annual number of CDHE days in China (brown line) and in the selected area (stations with increase trends in CDHE days, mainly in Southwest China, eastern Northwest China, northern North China and coastal area of southeastern China, red line) in warm season during 19612018, respectively. The map is generated using NCAR Command Language (The NCAR Command Language (Version 6.6.2) [Software]. (2019). Boulder, Colorado: UCAR/NCAR/CISL/TDD. https://www.ncl.ucar.edu/).

and the Middle and Lower Reaches of the Yangtze River is mainly due to increase in precipitation. Nevertheless, China has experienced more frequent and widespread CDHEs in general.

Additionally, the time series of the annual number of CDHE days in the warm season is shown in Fig. 3. For China as a whole, the frequency of CDHEs has increased with a trend of 5\%/10a, indicating that CDHEs has happened more frequently. The occurrence of CDHEs is relatively lower during the early 1970s to mid-1990s, but it has increased quickly since the late 1990s. Regionally, as shown in Fig. 2b, the increased frequency of CDHEs is mainly found in Southwest China, eastern Northwest China, northern North China, and the coastal area of southeastern China. To further investigate regional change features, time series in the number of CDHE days for the stations with an identified positive trend in Fig. $2 \mathrm{~b}$ (regard as selected area) is established. Results show that the trend in the occurrence of CDHEs in such stations is about 31\%/10a, which is 5 -time larger than the whole China average. Moreover, a greater increase in CDHEs frequency is observed since the late 1990s with the top 10 highest frequencies mostly in the twenty-first century. It indicates that compound events happen more frequently and significantly in Southwest China, eastern Northwest China, northern North China, and the coastal area of southeastern China, especially since the late 1990s.

To further analyze the change in spatial coverage of CDHEs, the time series of spatial area for CDHEs of different duration are provided in Fig. 4. As shown, the spatial extension of CDHEs is smaller than normal in the 1970s to mid-1990s, but larger in 1960s and late 1990s to 2010s. There is a non-significant increase trend $(0.1 \% / 10 \mathrm{a})$ in spatial area of CDHEs. However, the increasing trend is significant for persistent CDHEs. Specifically, the trend of the area coverage for persistent CDHEs is about 1.2\%/10a in China from 1961 to 2018. It implies that persistent CDHEs are occurring in more regions in China. Based on Fig. 3 and 4, it can be concluded that CDHEs have happened more widely and persistently in China, especially since the late 1990s.

As supported by the the previous studies ${ }^{40}$, the change in CDHE frequency and spatial extension before and after the late 1990s is likely related to the significant increase in both heat events and drought events in China since the late 1990s. The possible causes of the increase in China's heat events and drought events have been explained to be related to anthropogenic global warming and internal variabilities, such as the Pacific Decadal Oscillation and Atlantic Multidecadal Oscillation ${ }^{41-44}$.

Furthermore, the duration structure of CDHEs has changed since the late 1990s (Fig. 5). The change in the fractional contribution of non-persistent CDHEs shows more than normal before the 1990s (Fig. 5a). However, it has become less thereafter. Meanwhile, the fractional contribution of persistent CDHEs is less than normal before the 1990s and then it has increased since late 1990. As it is shown in Fig. 5b, the increasing trends for persistent CDHEs between 6 and 10 days are significant from 1961 to 2018. It can be concluded that fractional contribution has decreased for non-persistent CDHEs, while it has increased for persistent CDHEs. In general, CDHEs in China tend to happen more persistently in the warm season from 1961 to 2018.

\section{Conclusion and discussion}

In this study, a daily index reflecting the compound drought and heat event (CDHE) has been defined for the warm season based on the most updated daily temperature and drought index used operationally in China. This is different from the past studies which were based on a longer timescale drought background. It allows to more objectively reflect the changes in CDHEs and their persistence at daily timescale. Results reveal that CDHEs in China have become more frequent and more widespread, especially since the late 1990s. The increasing trend in 


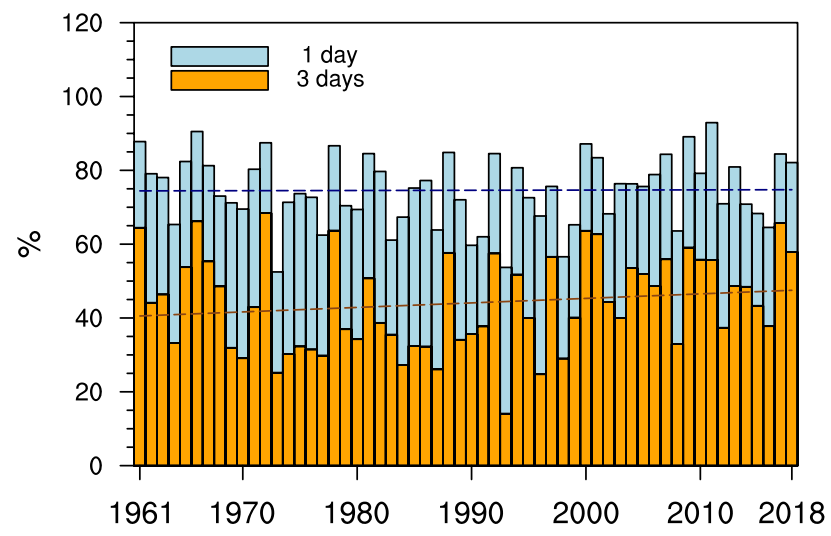

Figure 4. Time series of the spatial extension of CDHEs and persistent CDHEs in China in warm season during the time period of 1961-2018 (Lines refer to linear regression, blue and orange bars stand for CDHEs and persistent CDHEs, respectively). The map is generated using NCAR Command Language (The NCAR Command Language (Version 6.6.2) [Software]. (2019). Boulder, Colorado: UCAR/NCAR/CISL/TDD. https:// www.ncl.ucar.edu/).
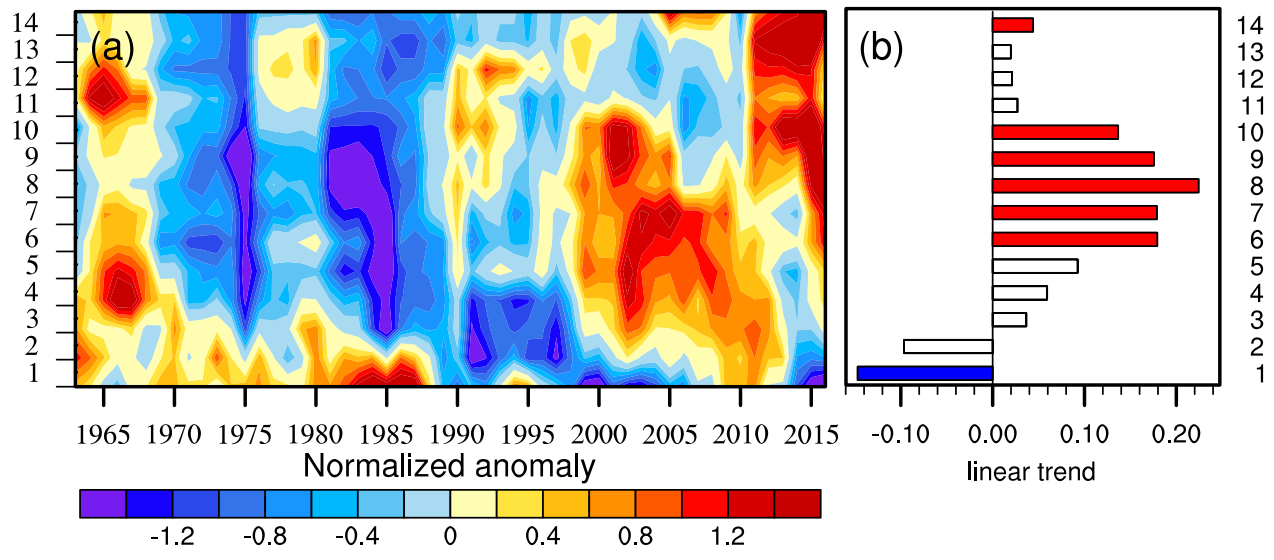

Figure 5. (a) temporal evolution of normalized anomaly of the fractional contribution of CDHEs with different duration to the total number of CDHE days for stations in China in warm season smoothed with a 5-year running mean, and (b) trend (\%/10a) in the normalized anomaly of the fractional contribution of CDHEs with different duration during the period of 1961-2018 (Filled bars stand for the station with statistical significance at $90 \%$ confidence level). Maps are generated using NCAR Command Language (The NCAR Command Language (Version 6.6.2) [Software]. (2019). Boulder, Colorado: UCAR/NCAR/CISL/TDD. https://www.ncl.ucar.edu/).

the frequency of CDHEs in China is 5\%/10a. We have also seen distinct regional features in the change of CDHEs in China as the increased frequency of CDHEs is more obvious in Southwest China, eastern Northwest China, northern North China, and coastal area of southeastern China, with a trend about 31\%/10a.

Such changing feature seems to link to changes in both heat events and drought events. Generally, either heat events or drought events in China has been increased since the late 1990s, possibly due to the combined effects of long term trend of global warming and multi-decadal/multi-annual variability (e.g. Pacific Decadal Oscillation, Atlantic Multidecadal Oscillation, and El Nino ${ }^{42,43,45}$. As a result, CDHEs have increased spatially and temporally.

Furthermore, CDHEs are found to have become more persistent. As CDHE is a concurrent event of drought and heat, some studies have already found that both heat and drought events in China have been prolonged during the past decade ${ }^{43,46}$ mainly because of global warming, the influence of ocean conditions, and regional land-use and land management changes. Noticeably, there may exist positive feedback between heat events and drought events ${ }^{47,48}$, especially under the global warming background. Self-intensification and self-propagation of compound events will exist with the aid of local and teleconnection feedback ${ }^{49}$. Possibly due to such reasons, CDHEs tend to happen more persistently under the background of increased drought and heat events since the late 1990s. Besides, soil moisture deficits before the onset of concurrent heat and dry extreme may also play an important role ${ }^{17}$. Understanding of these mechanisms will greatly support explain why CDHEs have increased and prolonged in China, especially in arid and semi-arid regions in China.

However, the interplay of multi-time scale variability and anthropogenic forcing on CDHEs is a complicated issue. Attribution study for change in compound extreme events such as CDHEs is still a challenging research topic. Meanwhile, a comprehensive understanding of the feedback between heat events and drought events under 


\begin{tabular}{|c|c|}
\hline Event & Definition \\
\hline Drought day & $\begin{array}{l}\text { Light drought : }-1.0<M C I<-0.5 \\
\text { Moderate drought: }-1.5<M C I \leq-1.0 \\
\text { Severe drought: }-2.0<M C I \leq-1.5 \\
\text { Extreme drought: } M C I \leq-2.0\end{array}$ \\
\hline Heat day & $\begin{array}{l}\text { Tmax }>\operatorname{Tmax}_{95} \\
\operatorname{Tmax}_{95} \text { refer to } 95 \text { percentile of daily maximum air temperature in the warm season } \\
\text { of } 1961-1990\end{array}$ \\
\hline Compound drought and heat event (CDHE) & $M C I \leq-0.5$ and $\operatorname{Tmax} \geq \operatorname{Tmax}_{95}$ \\
\hline K-day compound drought and heat event & $\begin{array}{l}\text { a K-day CDHE is defined if the CDHE persists for } K \text { days, then the CDHE terminates } \\
\text { when } M C I>-0.5 \text { or } \operatorname{Tmax}<\operatorname{Tmax}_{95}\end{array}$ \\
\hline Non-persistent compound drought and heat event & CDHE with a duration of 1- and 2-days \\
\hline Persistent compound drought and heat event & CDHE with a duration of longer than 2 days \\
\hline
\end{tabular}

Table 1. Summary of related definitions for compound drought and heat event.

the circumstance of CDHEs in China is insufficient and unclear at present. All these related studies in the future will improve the understanding of change in CDHEs at a regional scale and support climate change projection for extreme events, especially compound extreme events.

\section{Data and methods}

Data and definition. A long-term daily surface air temperature dataset consisting of 2,419 stations from 1961 to 2018 is obtained from China National Meteorological Information Center (NMIC). This dataset has been conducted rigorous quality control ${ }^{50}$. It has been widely used in the previous studies ${ }^{51,52}$. Additionally, an established drought index, the MCI dataset of 2,423 stations from 1961 to 2018 is provided by the National Climate Center of China. Different from some widely used drought index, such as standardized precipitation index $(\mathrm{SPI})^{53}$ and Palmer drought severity index $(\mathrm{PDSI})^{54}$, MCI provides a more objective drought index of daily scale and has been operationally used for drought monitoring in China for over 10 years $^{30,31}$.

Furthermore, some stations are not taken into account if: (1) they do not cover for the whole period from 1961 to 2018 , (2) stations have experienced relocation with their horizontal change beyond $20 \mathrm{~km}$ or vertical change over $50 \mathrm{~m}^{33}$, (3) total percentage of missing data during the period is over $5 \%$, (4) stations only include temperature data or MCI data. After those strict procedures, 1,250 stations are selected for this study. Based on MCI and maximum surface air temperature from 1961 to 2018, CDHE days are defined objectively as concurrent events of heat days and drought days (Related definitions are illustrated in Table 1).

Here, to derive a universal definition and to easily conduct spatial comparison for entire China, 95 percentile of daily maximum air temperature $\left(\operatorname{Tmax}_{95}\right)$ in the warm season of $1961-1990$ is used to define a heat day event. Based on this threshold, $\operatorname{Tmax}_{95}$ in about $90 \%$ stations is higher than $30^{\circ} \mathrm{C}$ and in about $45 \%$ stations over $35^{\circ} \mathrm{C}$. Only in few stations in the places over $3000 \mathrm{~km}$ elevation of the Tibetan Plateau region, $\operatorname{Tmax}_{95}$ is slightly below $25^{\circ} \mathrm{C}$. Nevertheless, such threshold has been also used to define high temperatures for a heat event locally ${ }^{55}$. Also, the percentile threshold definition for heat day is used in many recent studies related to compound event ${ }^{28,56}$.

Methods. To analyze the persistence change of the compound event, CDHEs are divided into 14 categories based on the number of persistent days from 1 to 14 days. CDHE lasting for more than 14 days is allocated into the category of 14-day CDHE. Additionally, for a given category $K$, the fractional contribution is calculated as the ratio of the total number of $K$-day CDHEs to the total number of CDHEs.

Following Zolina et al. ${ }^{32}$, normalized anomalies of the fractional contribution of CDHEs with different duration to the total number of CDHE days are calculated, derived from all selected stations in the warm season and smoothed with a 5-year running mean. If the fractional contribution of CDHEs with longer (shorter) duration is found to increase, it means that CDHEs tend to happen in a more persistent (non-persistent) way.

Additionally, the in situ observation network is dense in eastern China but scarce in western China. To avoid spatial sampling bias in whole country statistics, the percentage of the spatial coverage of CDHEs is calculated as a ratio of areal coverage of CDHEs to the valid observation area in China based on averages inside $1^{\circ} \times 1^{\circ}$ grids. The same approach also applied for persistent CDHEs's change study.

Received: 31 December 2019; Accepted: 12 August 2020

Published online: 03 September 2020

\section{References}

1. Wang, J. et al. Anthropogenically-driven increases in the risks of summertime compound hot extremes. Nat. Commun. 11(1), 528 (2020).

2. Fischer, E. M. \& Knutti, R. Detection of spatially aggregated changes in temperature and precipitation extremes. Geophys. Res. Lett. 41(2), 547-554 (2014).

3. Alexander, L. V. et al. Global observed changes in daily climate extremes of temperature and precipitation. J. Geophys. Res. Atmos. 111(D5), 1042-1063 (2006).

4. Forootan, E. et al. Understanding the global hydrological droughts of 2003-2016 and their relationships with teleconnections. Sci. Total. Environ. 650, 2587-2604 (2019). 
5. Mueller, B. \& Seneviratne, S. I. Hot days induced by precipitation deficits at the global scale. Proc. Natl. Acad. Sci. 109(31), 12398-12403 (2012)

6. Shi, J., Cui, L., Ma, Y., Du, H. \& Wen, K. Trends in temperature extremes and their association with circulation patterns in China during 1961-2015. Atmos. Res. 212, 259-272 (2018).

7. Yu, R., Zhai, P. M. \& Lu, Y. Y. Implications of differential effects between 1.5 and $2{ }^{\circ} \mathrm{C}$ global warming on temperature and precipitation extremes in China’s urban agglomerations. Int. J. Climatol. 38, 2374-2385 (2018).

8. Sun, P., Zhang, Q., Wen, Q. Z., Singh, V. P. \& Shi, P. J. Multisource data-based integrated agricultural drought monitoring in the Huai River Basin China. J. Geophys. Res. Atmos. 122, 10-751 (2017).

9. Wang, L., Chen, W., Zhou, W. \& Huang, G. Understanding and detecting super extreme droughts in southwest China through an integrated approach and index. Q. J. R. Meteorol. Soc. 142(694), 529-535 (2016).

10. Wang, W. W., Zhou, W., Li, X. Z., Wang, X. \& Wang, D. X. Synoptic-scale characteristics and atmospheric controls of summer heat waves in China. Clim. Dyn. 46, 2923-2941. https://doi.org/10.1007/s00382-015-2741-8 (2016).

11. Wang, L., Chen, W. \& Zhou, W. Assessment of future drought in Southwest China based on CMIP5 multimodel projections. Adv. Atmos. Sci. 31, 1035-1050 (2014).

12. Vogel, M. M., Zscheischler, J., Wartenburger, R., Dee, D. \& Seneviratne, S. I. Concurrent 2018 hot extremes across Northern Hemisphere due to human-induced climate change. Earth's Future. 7, 692-703 (2019).

13. Aghakouchak, A., Cheng, L. Y., Mazdiyasni, O. \& Farahmand, A. Global warming and changes in risk of concurrent climate extremes: insights from the 2014 California drought. Geophys. Res. Lett. 41(24), 8847-8852 (2014).

14. Fink, A. H. et al. The 2003 European summer heatwaves and drought?. Synop. Diagn. Impacts Weather 59(8), 209-216 (2010).

15. Mangani, R., Tesfamariam, E., Bellocchi, G. \& Hassen, A. Modelled impacts of extreme heat and drought on maize yield in South Africa. Crop Pasture Sci. 69, 703-716 (2018).

16. Zscheischler, J. et al. Future climate risk from compound events. Nat. Clim. Change 8, 469-477 (2018).

17. Russo, A., Gouveia, C. M. \& Dutra, E. The synergy between drought and extremely hot summers in the Mediterranean. Environ. Res. Lett. 14, 014011 (2019).

18. Hao, Z. C., Hao, F. H., Singh, V. P. \& Zhang, X. Changes in the severity of compound drought and hot extremes over global land areas. Environ. Res. Lett. 13, 124022 (2018).

19. Lyon, B. Southern Africa summer drought and heat waves: observations and coupled model behavior. J. Clim. 22, 6033-6046 (2009).

20. Mazdiyasni, O. \& Aghakouchak, A. Substantial increase in concurrent droughts and heatwaves in the United States. Proc. Natl. Acad. Sci. 112(37), 11484-11489 (2015).

21. Albright, T. P. et al. Combined effects of heat waves and droughts on avian communities across the conterminous United States. Ecosphere 1(5), 1-22 (2010).

22. Li, X. et al. Concurrent droughts and hot extremes in northwest China from 1961 to 2017. Int. J. Climatol. 39, $2186-2196$ (2019).

23. Lu, Y., Hu, H. C., Li, C. \& Tian, F. Q. Increasing compound events of extreme hot and dry days during growing seasons of wheat and maize in China. Sci. Rep. 8, 16700 (2018).

24. Kong, Q. Q. et al. Increases in summertime concurrent drought and heatwave in Eastern China. Weather Clim. Extremes 28, 100242 (2020).

25. Feng, S. F., Hao, Z. C., Zhang, X. \& Hao, F. H. Probabilistic evaluation of the impact of compound dry-hot events on global maize yields. Sci. Total Environ. 389, 1228-1234 (2019).

26. Sedlmeier, K., Feldmann, H. \& Schädler, G. Compound summer temperature and precipitation extremes over central Europe. Theor. Appl. Climatol. 131(24), 1493-1501 (2017).

27. Wang, S., Yuan, X. \& Wu, R. Attribution of the persistent spring-summer hot and dry extremes over northeast China in 2017. Bull. Am. Meteorol. Soc. 100(1), S85-S89 (2019).

28. Zscheischler, J. \& Seneviratne, S. I. Dependence of drivers affects risks associated with compound events. Sci. Adv. 3, e1700263 (2017).

29. Schubert, S. D., Wang, H., Koster, R. D. \& Suarez, M. J. Northern Eurasian heat waves and droughts. J. Clim. 27(9), 3169-3207 (2014).

30. General Administration of Quality Supervision, Inspection and Quarantine of the People's Republic of China \& China National Standardization Administration. GB /T 20481-2017 Grades of meteorological drought [ed. Zhang X. J. et al., S.] 5 (China Standard Press, 2017).

31. Liao, Y. M. \& Zhang, C. J. Spatio-temporal distribution characteristics and disaster change of drought in China based on meteorological drought composite index. Meteorol. Mon. 43(11), 1402-1409 (2017).

32. Zolina, O., Simmer, C., Gulev, S. K. \& Kollet, S. Changing structure of European precipitation: longer wet periods leasing to stronger extremes. Geophys. Res. Lett. 37(6), 460-472 (2010).

33. Chen, Y. \& Zhai, P. M. Changing structure of wet periods across southwest China during 1961-2012. Clim. Res. 61(2), 123-131 (2014).

34. Zhai, P. M., Zhang, X. B., Wan, H. \& Pan, X. H. Trends in total precipitation and frequency of daily precipitation extremes over China. J. Clim. 18(7), 1096-1108 (2005).

35. Wu, X., Hao, Z., Hao, F. \& Zhang, X. Variations of compound precipitation and temperature extremes in China during 1961-2014. Sci. Total Environ. 663, 731-737 (2019).

36. Wang, Y., Ren, F. \& Zhang, X. Spatial and temporal variations of regional high temperature events in China. Int. J. Climatol. 34(10), 3054-3065 (2014).

37. Zhang, H. Y., Wu, C. H. \& Hu, B. X. Recent intensification of short-term concurrent hot and dry extremes over the Pearl River basin China. Int. J. Climatol. https://doi.org/10.1002/joc.6116 (2019).

38. Li, M. X. \& Ma, Z. G. Decadal changes in summer precipitation over arid northwest China and associated atmospheric circulation. Int. J. Climatol. 38, 4496-4508 (2018).

39. Wang, L. J. et al. Increasing concurrent dought and heat in Huang-Huai-Hai Plain China. Int. J. Climatol. 38, 3177-3190 (2018).

40. Ding, T. \& Qian, W. Geographical patterns and temporal variations of regional dry and wet heatwave events in China during 1960-2008. Adv. Atmos. Sci. 28(2), 322-337 (2011).

41. Zhou, T., Ma, S. \& Zou, L. Understanding a hot summer in central eastern China: summer 2013 in context of multimodel trend analysis. Bull. Am. Meteorol. Soc. 95, S54 (2014).

42. Wang, W. W. et al. Statistical modeling and CMIP5 simulations of hot spell changes in China. Clim. Dyn. 44, 2859-2872. https:// doi.org/10.1007/s00382-014-2287-1 (2015).

43. Wang, M., Gu, Q., Jia, X. J. \& Ge, J. W. An assessment of the impact of Pacific decadal oscillation on autumn droughts in North China based on the Palmer drought severity index. Int. J. Climatol. 39(14), 5338-5350 (2019).

44. Shi, J. et al. Trends in the consecutive days of temperature and precipitation extremes in China during 1961-2015. Environ. Res. 161, 381-391 (2018).

45. Liu, J. \& Zhai, P. M. Changes in climate regionalization indices in China during 1961-2010. Adv. Atmos. Sci. 31(2), 374-384 (2014).

46. Zhang, J., Li, L., Wu, Z. W. \& Li, X. M. Prolonged dry spells in recent decades over north-central China and their association with a northward shift in planetary waves. Int. J. Climatol. 35(15), 4829-4842 (2015). 
47. Koster, R. D. et al. Flash drought as captured by reanalysis data: disentangling the contributions of precipitation deficit and excess evapotranspiration. J. Hydrometeorol. 20(6), 1241-1258 (2019).

48. Manning, C. et al. A Multivariate Description of Compound Events of Meteorological Drought and Heat Waves[C]//EGU General Assembly Conference Abstracts. 19, 17118 (2017).

49. Miralles, D. G., Gentine, P., Seneviratne, S. I. \& Teuling, A. J. Land-atmospheric feedbacks during droughts and heatwaves: state of the science and current challenges. Ann. N. Y. Acad. Sci. 1436(1), 19 (2019).

50. $\mathrm{Xu}, \mathrm{W} . \mathrm{H}$. et al. Homogenization of Chinese daily surface air temperatures and analysis of trends in the extreme temperature indices. J. Geophys. Res. Atmos. 118(17), 9708-9720 (2013)

51. Zhai, P. M. et al. The strong El Nino of 2015/16 and its dominant impacts on global and China's climate. J. Meteor. Res. 30(3), 283-297 (2016).

52. Li, Q. X. et al. China experiences the recent warming hiatus. Geophys. Res. Lett. 42(3), 889-898 (2015).

53. Guttman, N. B. Accepting the standardized precipitation index: a calculation algorithm. J. Am. Water Resour. Assoc. 35, 311-322. https://doi.org/10.1111/j.1752-1688.1999.tb03592.x (1999).

54. Palmer, W. C. Meteorological Drought. Research Paper No. 45, US Weather Bureau, Washington, DC (1965).

55. Song, S. Y. Tebet Climete (ed.Song, S. Y) 147 (China Meteorolocial Press, 2013).

56. Sun, C. X. et al. Drought occurring with hot extremes: changes under future climate change on Loess Plateau, China. Earth's Future 7(6), 587-604 (2019).

\section{Acknowledgements}

This work was jointly supported by the National Key Research and Development Program of China (Grant No.: 2018YFC1507700) and the National Natural Science Foundation of China (Grant No. 41905083).

\section{Author contributions}

R.Y. designed the research, performed the analysis, drafted and revised the manuscript. P.Z. designed the research, provided comments and revised the manuscript.

\section{Competing interests}

The authors declare no competing interests.

\section{Additional information}

Correspondence and requests for materials should be addressed to P.Z.

Reprints and permissions information is available at www.nature.com/reprints.

Publisher's note Springer Nature remains neutral with regard to jurisdictional claims in published maps and institutional affiliations.

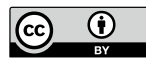

Open Access This article is licensed under a Creative Commons Attribution 4.0 International License, which permits use, sharing, adaptation, distribution and reproduction in any medium or format, as long as you give appropriate credit to the original author(s) and the source, provide a link to the Creative Commons licence, and indicate if changes were made. The images or other third party material in this article are included in the article's Creative Commons licence, unless indicated otherwise in a credit line to the material. If material is not included in the article's Creative Commons licence and your intended use is not permitted by statutory regulation or exceeds the permitted use, you will need to obtain permission directly from the copyright holder. To view a copy of this licence, visit http://creativecommons.org/licenses/by/4.0/.

(c) The Author(s) 2020 